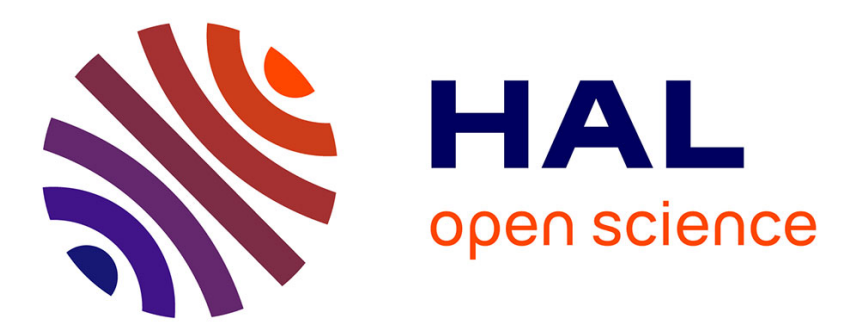

\title{
Effect of polycarboxylate and crushed quartz in UHPC: Microstructural investigation
}

Mireille Courtial, Marie-Noëlle de Noirfontaine, Frédéric Dunstetter, Marcel

Signes-Frehel, Pierre Mounanga, Khalid Cherkaoui, Abdelhafid Khelidj

\section{- To cite this version:}

Mireille Courtial, Marie-Noëlle de Noirfontaine, Frédéric Dunstetter, Marcel Signes-Frehel, Pierre Mounanga, et al.. Effect of polycarboxylate and crushed quartz in UHPC: Microstructural investigation. Construction and Building Materials, 2013, 44, pp.699-705. 10.1016/j.conbuildmat.2013.03.077 . hal-03284766

\section{HAL Id: hal-03284766 https://hal.science/hal-03284766}

Submitted on 18 Aug 2021

HAL is a multi-disciplinary open access archive for the deposit and dissemination of scientific research documents, whether they are published or not. The documents may come from teaching and research institutions in France or abroad, or from public or private research centers.
L'archive ouverte pluridisciplinaire HAL, est destinée au dépôt et à la diffusion de documents scientifiques de niveau recherche, publiés ou non, émanant des établissements d'enseignement et de recherche français ou étrangers, des laboratoires publics ou privés.

\section{(c)(1)}

Distributed under a Creative Commons Attribution| 4.0 International License 


\title{
Effect of polycarboxylate and crushed quartz in UHPC: Microstructural investigation
}

\author{
M. Courtial ${ }^{\mathrm{a}, \mathrm{b}, *}$, M.-N. de Noirfontaine $^{\mathrm{b}}$, F. Dunstetter $^{\mathrm{b}}$, M. Signes-Frehel $^{\mathrm{b}}{ }^{\text {, P. }}$ Mounanga $^{\mathrm{c}}$, \\ K. Cherkaoui ${ }^{\text {b,c }}$, A. Khelidj ${ }^{\mathrm{c}}$ \\ a Université d'Artois, 1230 rue de l'Université, BP 819, 62408 Béthune, France \\ ${ }^{\mathrm{b}}$ Laboratoire des Solides Irradiés, CNRS UMR 7642-CEA-Ecole Polytechnique, Ecole Polytechnique, 91128 Palaiseau Cedex, France \\ ${ }^{c}$ GeM, CNRS UMR 6183-Université de Nantes-IUT Saint-Nazaire, 58 rue Michel Ange, 44606 Saint-Nazaire, France
}

\begin{abstract}
The context of this study was to find an extrudable formulation of Ultra High Performance Concretes usable in an aggressive environment. In the five mixtures of this study, the only variable parameters are the polycarboxylate (PCE) dosage and the crushed quartz to micro silica ratio. This paper is devoted to a systematic microstructural study using Scanning Electronic Microscopy (SEM), with the idea to link the microstructure with the macroscopic results. Through this study, the effect of the polycarboxylate on the hydration of the type of cement used here is pointed out. From $1.8 \%$ to $2 \%$ polycarboxylate content, we observe a change in the hydration time for the two calcium silicates, the major phases of anhydrous cement. In the presence of microsilica and with $2 \mathrm{wt}$.\% PCE, we observe a higher consumption of dicalcium silicate, which should not have reacted with such a low water content (Water/Cement $=0.16$ ).
\end{abstract}

\section{Introduction}

Ultra High Performance Concretes (UHPC) introduced by Richard and Cheyrezy [1] in the nineties are defined as concretes with a compressive strength higher than $150 \mathrm{MPa}$ [2]. UHPC can be used to build differently, in situations where no other concrete can fulfil the technical or architectural requests. Using the self-placing character of UHPC, one can create thin, light manufactured pieces with various shapes, which reduces the execution time and weight structure. More and more applications can be found throughout the world, especially bridges or net facades or net roofs appreciated by architects at the present time. From the sustainability point of view, a UHPC contains three times more cement per $\mathrm{m}^{3}$

* Corresponding author at: Université d'Artois, 1230 rue de l'Université, BP 819, 62408 Béthune, France. Tel.: +33 321632337.

E-mail address: mireille.courtial@polytechnique.edu (M. Courtial). than ordinary concrete, thus using three times more energy and producing three times more $\mathrm{CO}_{2}$. However, as long as the required quantity is divided at least by a factor three, the balance sheet remains favourable. One can even expect a better ratio taking into account its exceptional durability, thus supposing lower maintenance cost for the service life time of the structure. Moreover, one can also expect to be able to use the demolished materials as high quality recycled granulates for new concrete.

The progress of water reducers makes it possible to keep a good workability at low water to cement ratio (W/C). In a UHPC, W/C typically lies in the $0.15-0.21$ range and polycarboxylates were found to be the most effective superplasticizers for this kind of concrete.

Excellent performance of UHPC in terms of strength and durability are based on the search for a minimal porosity. Two distinct approaches are combined: 
- The size of aggregates. Summarizing the parameters of numerous types of concrete, Richard and Cheyrezy [3] found that the crack size is proportional to the maximum aggregate size. In this way, one can consider that a first principle for the design of UHPC is to divide the size of the largest aggregate by a factor 100 , with a grain size below $650 \mu \mathrm{m}$.

- Maximizing the density of the granular packing [4]. Instead of the three grain sizes - gravel, sand and cement - found in ordinary concrete, UHPC exhibit four grain sizes: sand, cement, crushed quartz and silica fume (microsilica). Silica fume is added in order to fill the space between the smallest grains. Since 2002, an additional millimetric grain size can also be added to UHPC.

For UHPC, with compressive strength in the range 150$200 \mathrm{MPa}$, i.e. without any subsequent treatment, the direct result of hydration on porosity is as follows: due to the low $\mathrm{W} / \mathrm{C}$, the capillary porosity disappears and the Interface Transition Zone (ITZ) is filled up with $\mathrm{C}-\mathrm{S}-\mathrm{H}$ hydrates produced by the pozzolanic reaction of silica fume. In order to improve the performance of UHPC and attain this performance more rapidly [5], a thermal treatment can be performed. Above $90^{\circ} \mathrm{C}$, a pozzolanic reaction of crushed quartz occurs; above $200^{\circ} \mathrm{C}$, one observes a decreasing of the $\mathrm{C}-\mathrm{S}-\mathrm{H}$ inter-layer spacing, together with an increasing of the C$\mathrm{S}-\mathrm{H}$ crystallinity. A last treatment consists in a compressive treatment performed either before or during the setting, in order to eliminate the air bubbles introduced by the concrete placing and the first cracks arising from the chemical shrinkage during setting.

Another key point is the high value of the Young's modulus (50$60 \mathrm{GPa}$ ) observed on UHPC, which is a result of (i) the choice of the mineralogy of sand and mainly and (ii) the large amount of remaining clinker which acts as an ideal aggregate, owing to its high own Young's modulus. However the consequence is a high fragility. Introducing microfibers allows achievement of a high ductile concrete at the macroscopic scale (flexural strength: 30$55 \mathrm{MPa}$ ) together with high compressive strength [6].

Finally, let us mention an important property of UHPC: its selfhealing capability. The residual clinker is able to react with external water flowing through cracks appearing later during the life of the material [7].

The aim of this study is to investigate extrudable UHPC for the manufacture of concrete pipes for use in aggressive environments. We started from the granular composition optimized by Richard and Cheyrezy [3]: cement: 1 , sand: 1.1 , silica fume: 0.25 (cement mass ratio). Instead of a polyacrylate superplasticizer, Morin et al. [8] and Feylessoufi et al. [9] used a new generation of superplasticizer, a polycarboxylate (PCE) with variable mass proportions, i.e., $0.5 \%, 1 \%$ and $1.5 \%$ for $\mathrm{W} / \mathrm{C}=0.2$, and $1.8 \%$ for $\mathrm{W} / \mathrm{C}=0.16$.

We selected five compositions based on these studies at $\mathrm{W} / \mathrm{C}=0.16$ referred to as UHPC1 to UHPC5 [10]. For the UHPC1, UHPC2 and UHPC3 formulations, the only varying parameter is the PCE content, in the range 0.5-1.8\%. In the two UHPC4 and UHPC5 formulations, a fixed portion (1/4) of silica fume is replaced by crushed quartz, whereas the PCE content is modified from $1.8 \%$ (UHPC4) to $2 \%$ (UHPC5).

Using these five selected formulations, two series of investigations have been performed:

- A study of several properties of these materials: extrudability, microcalorimetry, shrinkage, mechanical properties (strength and Young's modulus) and durability (gas and water permeability). This study is detailed elsewhere [11]. It is shown that replacing silica fume by crushed quartz enhances all the properties, with the best results for the UHPC4 formulation. The UHPC3 formulation is not extrudable unlike the four others.
- A systematic study of their microstructure has been carried out using Scanning Electron Microscopy (SEM) together with X-ray Powder Diffraction (XRD). The SEM results are presented here. The aim of this paper is to link the microstructure and the effect of the superplasticizer content and the crushed quartz substitution on the performance. The effect of the polycarboxylate content on the hydration of the type of cement used here is also pointed out.

Many SEM studies can be found in the open literature about UHPC, most of them being devoted to (i) the paste-fiber binding [12-14], (ii) the effect of substitution or addition of the raw materials (first recommended by Richard and Cheyrezy [3]) by sustainable materials [15-20] and (iii) going with thermal or pressure treatments. Matte et al. [21,22] investigated the lixiviation effects. Müller et al. [23] studied heat-treated and autoclaved UHPC samples. Using an Environmental SEM, Möser et al. [24] investigated the stages of hydration. Sorelli et al. [25] described the industrial materials they used to measure the Young's modulus by nanoindentation.

This study is devoted to UHPC samples cured at room temperature for at least 3 months.

\section{Materials and methods}

\subsection{Materials and mixtures}

The UHPC samples studied were prepared using Portland cement CEM I $52.5 \mathrm{~N}$ CE PM-ES-CP2 NF (produced by Lafarge in the Le Havre plant), amorphous white silica fume (Condensil), crystalline crushed quartz powder (C500, Sibelco), siliceous sand (CV32, Sibelco), polycarboxylate superplasticizer (PCE), and water $(\mathrm{W} / \mathrm{C}=0.16)$. The superplasticizer is the Cimfluid 2002 of Axim-Italcementi, in liquid form (dry matter 35\%). The fineness $(S)$, the density $(\rho)$ and the particle size of the solid compounds are given in Table 1 and Fig. 1 . To use a low W/C such as 0.16 in UHPC, particularly slightly milled cement is required.

The chemical and mineralogical analysis of the cement is given in Table 2. Silica fume (white colored) contains $93.50 \%$ of amorphous $\mathrm{SiO}_{2}$ and $6.10 \%$ of minor oxides. The two calcium silicates $\mathrm{C}_{3} \mathrm{~S}$ (alite) and $\mathrm{C}_{2} \mathrm{~S}$ (belite) and the two calcium aluminates $\mathrm{C}_{3} \mathrm{~A}$ and $\mathrm{C}_{4} \mathrm{AF}$ are written in the cement notations $\left(\mathrm{C}=\mathrm{CaO}, \mathrm{S}=\mathrm{SiO}_{2}\right.$, $\mathrm{A}=\mathrm{Al}_{2} \mathrm{O}_{3}, \mathrm{~F}=\mathrm{Fe}_{2} \mathrm{O}_{3}$ ). The cement has a very low $\mathrm{C}_{3} \mathrm{~A}$ content to decrease both the hydration heat and the ettringite formation. The low alcali and sulphate contents

Table 1

Specific area $(S)$ and density $(\rho)$ of the solid compounds of UHPC provided by the producers.

\begin{tabular}{lrl}
\hline Materials & $S\left(\mathrm{~cm}^{2} / \mathrm{g}\right)$ & $\rho\left(\mathrm{g} / \mathrm{cm}^{3}\right)$ \\
\hline Cement & 3820 & 3.2 \\
Sand & 126 & 2.65 \\
Crushed quartz & 10,300 & 2.65 \\
Silica fume & 140,000 & 2.2 \\
\hline
\end{tabular}

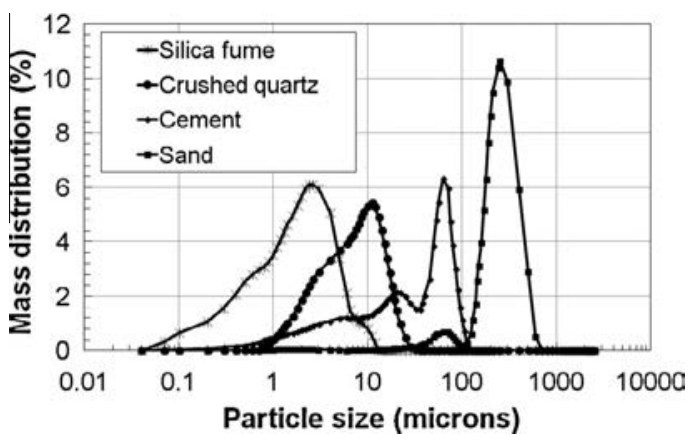

Fig. 1. Particle size distribution of the UHPC components, measured by laser granulometry. 
Table 2

Chemical analysis and Bogue mineralogical composition (\% in mass) of the cement.

\begin{tabular}{lllllllll}
\hline Oxydes & $\mathrm{CaO}$ & $\mathrm{SiO}_{2}$ & $\mathrm{Al}_{2} \mathrm{O}_{3}$ & $\mathrm{Fe}_{2} \mathrm{O}_{3}$ & $\mathrm{MgO}$ & $\mathrm{K}_{2} \mathrm{O}$ & $\mathrm{SO}_{3}$ & $\mathrm{Na}_{2} \mathrm{O}$ \\
Cement & 64.58 & 21.39 & 3.66 & 4.25 & 0.96 & 0.28 & 2.63 & 0.10 \\
Phases & $\mathrm{C}_{3} \mathrm{~S}$ & $\mathrm{C}_{2} \mathrm{~S}$ & $\mathrm{C}_{3} \mathrm{~A}$ & $\mathrm{C}_{4} \mathrm{AF}$ & Gypse & $\mathrm{CaCO}_{3}$ & & \\
Cement & 67.5 & 10.7 & 2.64 & 12.8 & 3.3 & 1.5 & & \\
\hline
\end{tabular}

Table 3

Composition of the five selected UHPC expressed in terms of component to cement mass ratio (cement $=1$, sand $=1.1, W / C=0.16$ ). The additional sample referred to UHPC3' is discussed in Section 3.3.

\begin{tabular}{llll}
\hline UHPC & Silica fume & Crushed quartz & PCE (\%) \\
\hline UHPC1 & 0.25 & 0 & 0.5 \\
UHPC2 & 0.25 & 0 & 1 \\
UHPC3 & 0.25 & 0 & 1.8 \\
UHPC4 & $0.25 \times 3 / 4$ & $0.25 \times 1 / 4$ & 1.8 \\
UHPC5 & $0.25 \times 3 / 4$ & $0.25 \times 1 / 4$ & 2 \\
UHPC3' & 0.25 & 0 & 2 \\
\hline
\end{tabular}

promote the cubic symmetry of $C_{3} A$, which is less reactive than the orthorhombic form, and decrease the ettringite production. Moreover, the cement contains a low limestone filler content to active the hydration kinetic.

The composition of the five UHPC mixtures investigated is given in Table 3. The batch mixing procedure is described elsewhere [11].

\subsection{Methods}

The microstructure of the UHPC samples was observed on polished sections and fractures. The material is embedded in ultra-low viscosity epoxy resin by vacuum impregnation. Once the resin has hardened, a sequence of fine particle size diamond polishing pastes is used in order to get the required flat surface. Finally, the samples are sputtered with gold in order to lower the charging effect under the electron beam.

The SEM examinations were performed using a Field Emission Scanning Electron Microscope (FESEM, Model Hitachi S-4800), with either secondary electron (SE) (topological contrast) or backscattered scanning electron (BSE) imaging (chemical contrast). X-ray microanalysis (EDX) is also performed. The accelerating voltage is $10 \mathrm{kV}$ for imaging and $15 \mathrm{kV}$ for EDX. The photographs presented here are representative images of the microstructure, since we prepared large polished sections (1,2-in. diameter) and we collected more than 100 images per sample.

All the samples have also been studied by X-ray Diffraction (XRD) using a Panalytical X'Pert Pro diffractometer equipped with a Co tube $(K \alpha 1, K \alpha 2)$.

\section{Results}

The very low $\mathrm{W} / \mathrm{C}$ rapidly limits the hydration reactions. The degree of hydration as calculated using the Powers model corrected by Jensen and Hansen [26] is low: $\alpha=0.28$ for the UHPC1, UHPC 2 and UHCP3 compositions; $\alpha=0.3$ for the UHPC 4 and UHPC5 compositions. Such an $\alpha$ value represents a $682-695 \mathrm{~kg} / \mathrm{m}^{3}$ amount of anhydrous cement at the end of hydration. The volume fractions of anhydrous cement, silica fume, hydrate, gel porosity, capillary porosity and chemical shrinkage are sketched in Fig. 2. The porosity of the five fresh compositions (respectively 3.3\%, 3.95\%, 5.15\%, 4.65\% and $4.97 \%$ ) exhibit values between $3.3 \%$ and $5 \%$ in the same range as the range reported by Resplendino and Petitjean [27].

\subsection{UHPC1 to UHPC3}

In this series of compositions, the only modified parameter is the polycarboxylate (PCE) content, which increases from $0.5 \%$ to $1.8 \%$. The extremely compact microstructure of a UHPC can be observed on the SEM examination of the samples of this series.

As an example, Fig. 3 shows back-scattered electron images of UHPC1 samples.

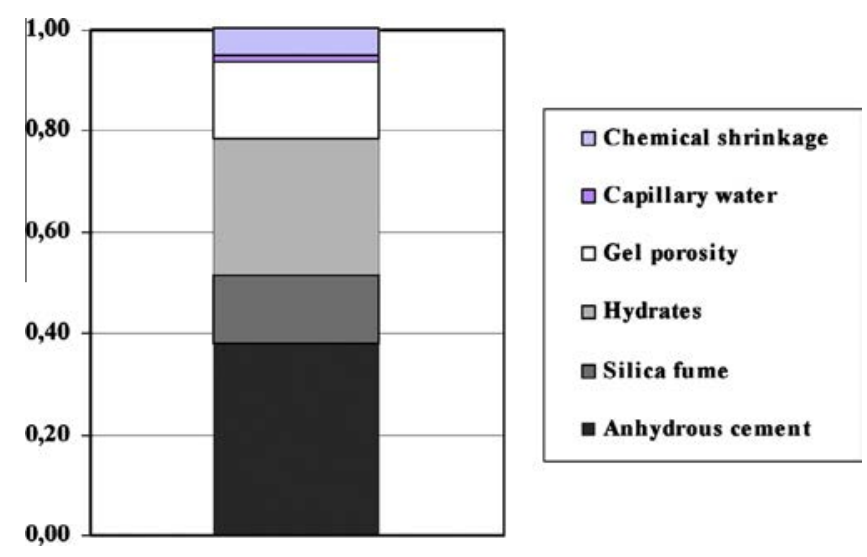

Fig. 2. Volumetric phases distribution of a UHPC according to the Powers-Jensen model.

(a)

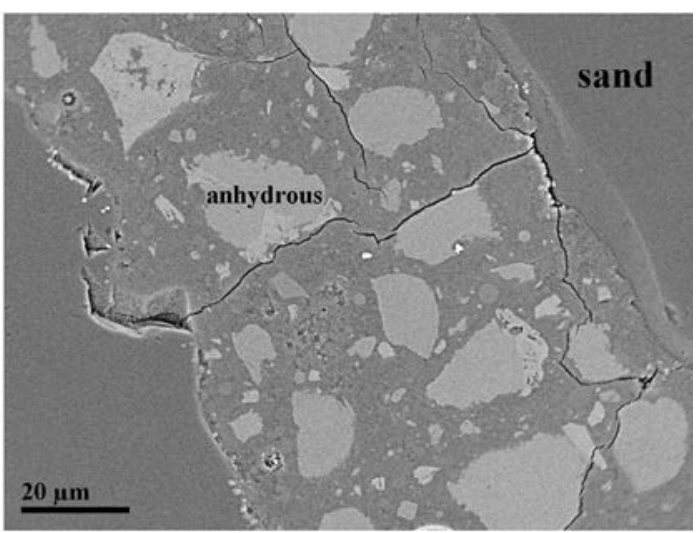

(b)

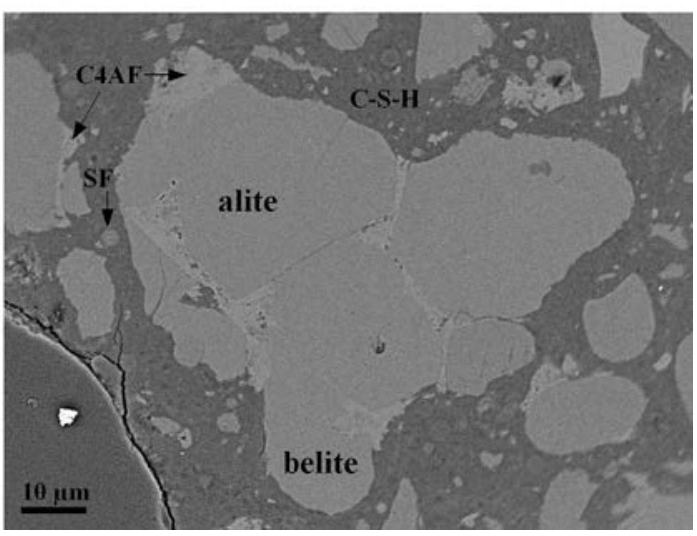

Fig. 3. Back-scattered electron images of UHPC1 sample (polished sections): (a) sand and paste with many anhydrous clinker grains. (b) Polymineralic grain of clinker containing alite, belite and $\mathrm{C}_{4} \mathrm{AF}$ (light grey), silica fume noted SF (middle grey), and C-S-H (dark grey).

The (dark grey) sand grains are well dispersed in the paste. The paste between the sand grains exhibits a good homogeneity and contains:

- A lot of anhydrous cement (light grey).

- Hydrate compounds (medium grey).

- Silica fume well dispersed by the effect of the polycarboxylate superplasticizer.

- ITZ well filled by hydrates arising from the pozzolanic reaction of silica fume.

- Micro-cracks bypassing the anhydrous grains, arising from the sample preparation. 
These features are found in all the UHPC1 to UHPC3 samples, except for the occluded air, which is found in increasing proportion from the UHPC1 to the UHPC3 compositions, due to the increasing superplasticizer content.

As described by Scrivener and Kirkpatrick [28] we observe the clinker grains either as polymineralic grains (3b) or as isolated monomineralic grains of alite, belite and aluminates. One clearly observes the characteristic polygonal shape of the alite crystals and the round-shaped belite crystals. Gypsum crystals are never found, which indicates that gypsum totally reacted with the aluminates.

Among the various hydrates, only $\mathrm{C}-\mathrm{S}-\mathrm{H}$ hydrates are well visible on polished sections. On fracture preparations (Fig. 4), the silica fume hydration is only superficial: we observe (Fig. 4a) silica fume spheres varying from $5 \mu \mathrm{m}$ down to $50 \mathrm{~nm}$, with only superficial C-S-H coverage. Silica fume is only slightly hydrated in spite of the high alkalinity on the paste. We observe only scarce portlandite crystals and only fine needles like ettringite crystals. Portlandite crystals are visible only in the largest pores, inside the entrapped air bubbles. A typical large crystal of alite, with little surface hydrates, is shown at Fig. 4b.

Powder X-ray diffraction analysis shows the M1 polymorph for alite, with the $\langle\mathrm{M}\rangle$ Pc structure as described by de Noirfontaine et al. [29]. It clearly appears in the specific angular windows (Fig. 5) defined by Courtial et al. [30], where the characteristic lines (referred to as E, F and I lines) of the M1 polymorph are found. Such a result is consistent with the chemical composition of the clinker [31]: $1.56 \% \mathrm{SO}_{3}$ and $0.91 \% \mathrm{MgO}$ (private communication).

\subsection{UHPC4 and UHPC5}

In this series, crushed quartz is partially substituted (25\%, see Table 3 ) for silica fume. Here, the only modified parameter is the polycarboxylate (PCE) content: $1.8 \%$ and $2 \%$. Concerning the microstructure observation, the main features are similar to what was
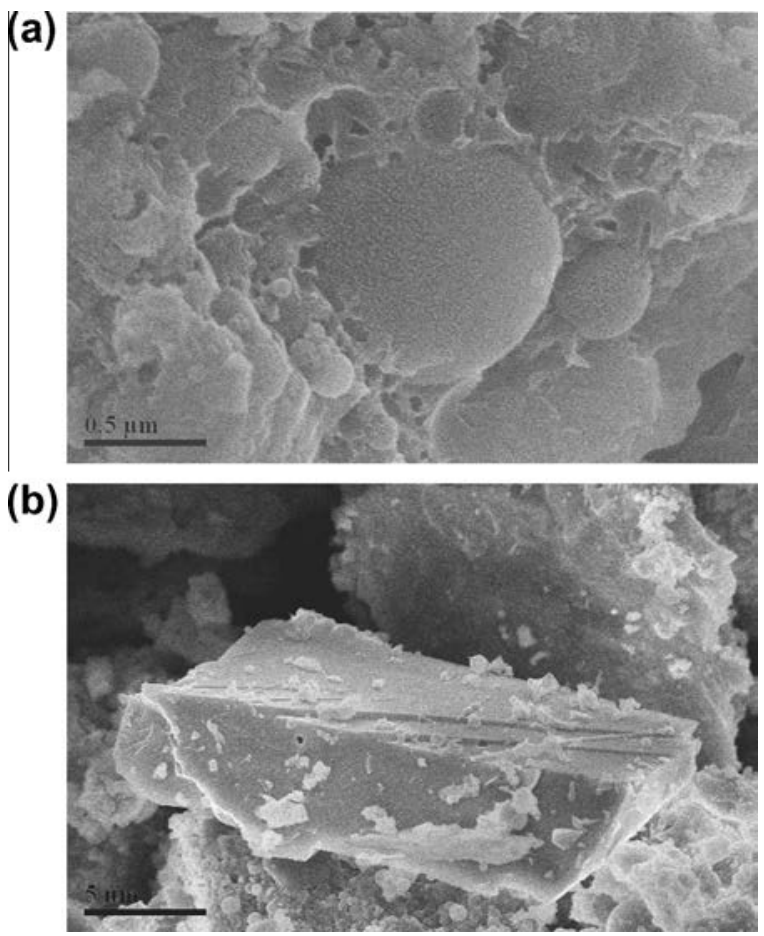

Fig. 4. Secondary electron images in the UHPC3 paste (fractures): (a) silica fume and $\mathrm{C}-\mathrm{S}-\mathrm{H}$ hydrates and (b) crystal of alite, silica fume and hydrates.
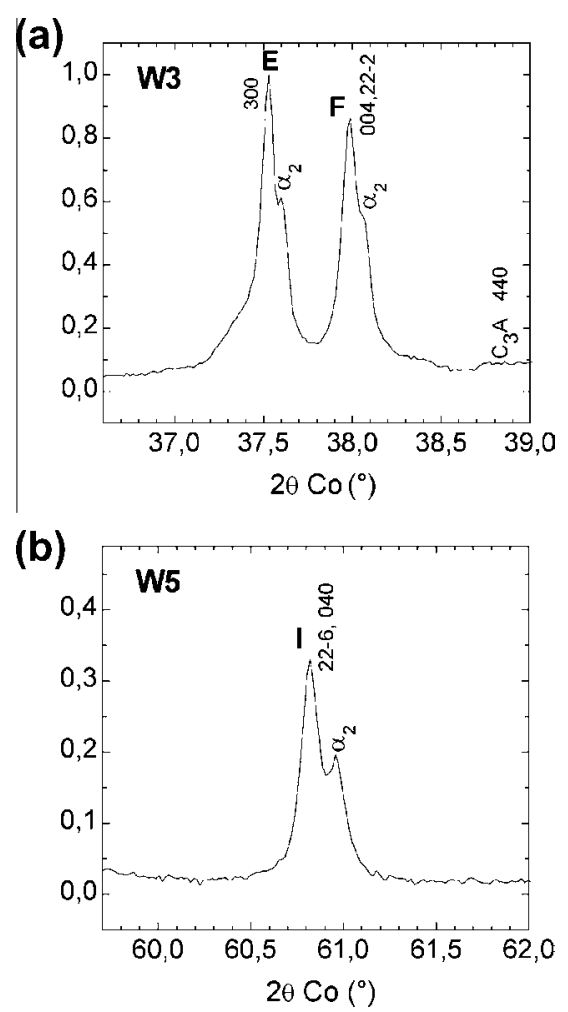

Fig. 5. Powder X-ray diffraction of the cement investigated in this study. The angular windows (a) W3 and (b) W5, as defined by Courtial et al. [30], exhibit the characteristic lines (E, F and I) of the M1 polymorph of alite. The hkl indexes are related to the $\langle\mathrm{M}\rangle$ Pc unit cell as described by de Noirfontaine et al. [29].

found in the first series of samples (UHPC1 to UHPC3), except the presence of crushed quartz.

Between the two compositions of the series, UHPC4 and UHPC5, two major differences are observed concerning the microstructure (Fig. 6):

(i) The crushed quartz distribution is homogeneous throughout the UHPC4 paste (Fig. 6a), whereas it is very heterogeneous in the UHPC5 paste (Fig. 6b). In the latter, the crushed quartz is preferentially located at close contact with the sand grains, in the ITZ. The crushed quartz is easily recognizable on secondary electron micrographs due to its brilliant contrast related to charging effects. EDX analysis of quartz systematically exhibits a high $\mathrm{Na}$ content, the $\mathrm{Na}^{+}$ion being the counter-ion of the polycarboxylate ion. We systematically found a rod-like shape for the crushed quartz grains (Fig. 6c) in backscattered electrons mode.

(ii) The cement hydration is different for the two compositions. In UHPC5, only very few belite crystals remain, in polymineralic grains and also in monomineralic grains (Fig. 6c and $\mathrm{d}$ ). This observation is confirmed by X-ray diffraction. All the diffraction lines of belite considerably decrease in the diffraction pattern of UHPC5 samples.

\subsection{UHPC3'}

One wonders if the promotion of belite hydration is related to the polycarboxylate content only or/and to the presence of crushed quartz. This is why we synthesized a supplementary mixture (named UHPC-3') similar to the UHPC3 mixture (i.e. without crushed quartz), but with a $2 \%$ polycarboxylate content instead of the $1.8 \%$ content used in the UHPC 3 mixture. Once again we observe a decrease in the belite content by XRD. 
(a)

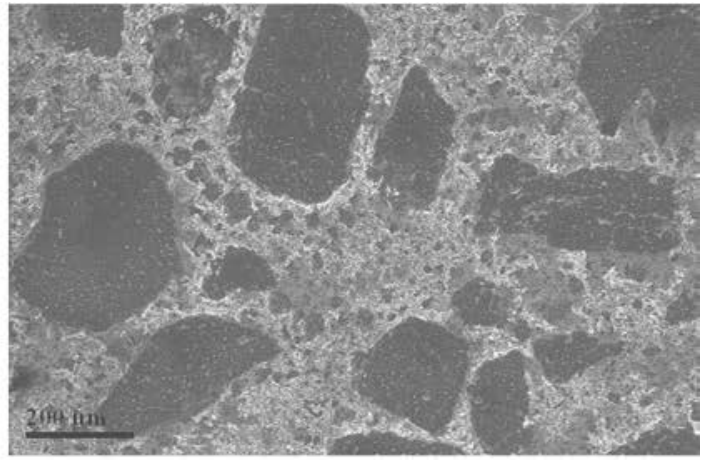

(b)

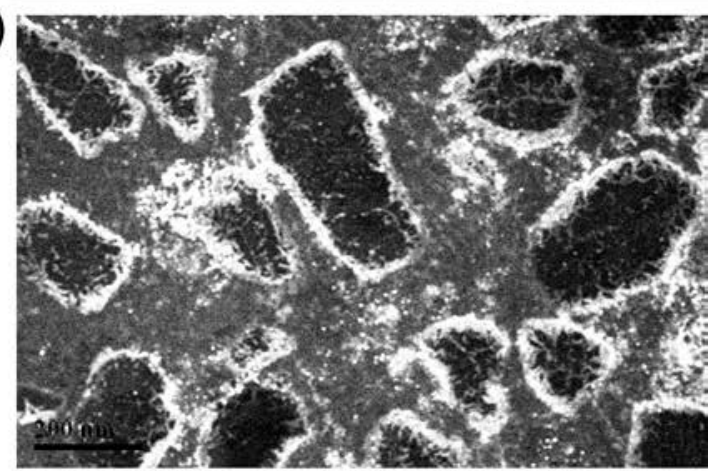

(c)

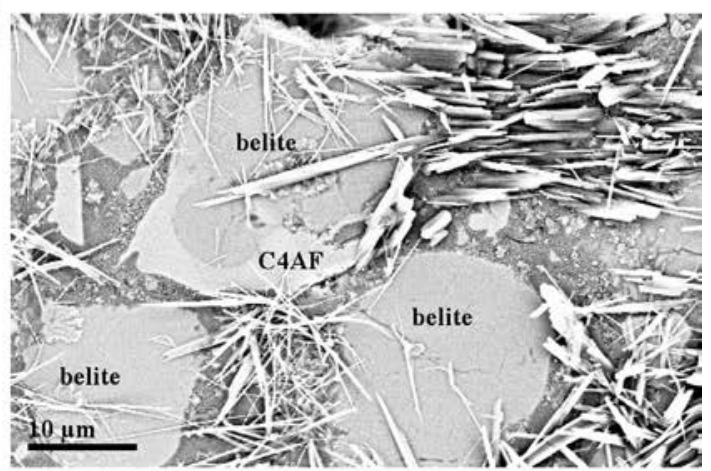

(d)

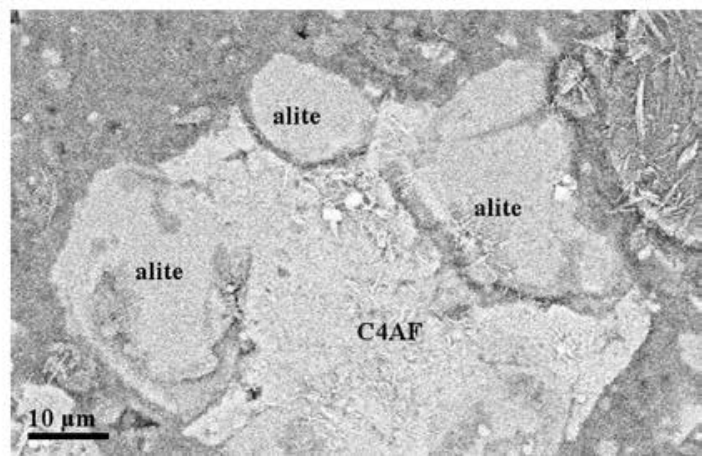

Fig. 6. Micrographs of UHPC4 and UHPC5 samples. (a and b) Secondary electron images: homogeneous versus heterogeneous crushed quartz repartition. In UHPC5, crushed quartz is preferentially fixed to the sand. (c and d) Back-scattered electron images: residual clinker. Belite is very visible in UHPC4 and difficult to find in UHPC5.

\section{Discussion}

4.1. Effects of polycarboxylate and crushed quartz contents on short and long term performance of UHPC

This part discusses the link between the microstructure observed here and some of properties previously measured in Ref. [11] and summarized in Table 4: consistency versus extrudability,
Table 4

Properties of the five selected UHPC. The first column provides a quality label for the consistency of the material relative to extrudability. The extrudability of each UHPC is given in column 2. The three others columns give the compressive and flexural strength $\left(R_{\mathrm{c}}\right.$ and $\left.R_{\mathrm{f}}\right)$ and the dynamic Young's modulus $\left(E_{\mathrm{dyn}}\right)$.

\begin{tabular}{llllll}
\hline UHPC & $\begin{array}{l}\text { Consistency/ } \\
\text { extrudability }\end{array}$ & Extrudability & $R_{\mathrm{c}}(\mathrm{MPa})$ & $R_{\mathrm{f}}(\mathrm{MPa})$ & $E_{\text {dyn }}(\mathrm{GPa})$ \\
\hline UHPC1 & Good & Yes & 155 & 19 & 54 \\
UHPC2 & Good & Yes & 150 & 19 & 59 \\
UHPC3 & Too fluid & No & 140 & 19 & 60 \\
UHPC4 & Very good & Yes & 175 & 22 & 69 \\
UHPC5 & Good & Yes & 170 & 21 & 65 \\
\hline
\end{tabular}

extrudability, compressive and flexural strengths and Young's modulus for UHPC (1-5).

The first point is the effect of the polycarboxylate and crushed quartz contents on extrudability. A detailed account of the extrudability measurements is given in reference [11]. The difference of extrudability between UHPC3 and UHPC4 (1.8\%SP) can be explained by a better viscosity of the UHPC4 paste when substituting $25 \%$ of the round shaped silica fume by rough crushed quartz. For a same content of crushed quartz, UHPC5 ( $2 \%$ SP) was found to be more easily extrudable than UHPC4 $(1.8 \% \mathrm{SP})$ but the extruded UHPC5 is deformable. Our microstructural analysis brings a key for the understanding of this behaviour. The crushed quartz is found in the ITZ (Fig. 6b) for UHPC5 instead of in the paste (Fig. 5a) for UHPC4, with the result of increasing the flowability of the UHPC5 mixture and decreasing the pressure needed for its extrusion.

The second point concerns both mechanical strength and rigidity of the material [11]. The main consequence of the substitution of $25 \%$ of silica fume by crushed quartz in $\operatorname{UHPC}(4-5)$ is to increase the compressive and flexural strengths by a factor of about $20-25 \%$ versus UHPC(1-3) (Table 4). With crushed quartz, an additional grain size is found, intermediate between the grain sizes of cement and silica fume. The result is to increase the density of the initial packing and thereby the final density of UHPC. This phenomenon is more efficient when the crushed quartz is homogeneously distributed in the paste. This is probably why the mechanical strength is higher in UHPC4 than UHPC5.

As can be seen in Fig. 3a, the microcracks bypass the anhydrous grains, since these grains are stiffer than the hydrates $\left(E_{\mathrm{anh}}=125-\right.$ $145 \mathrm{GPa}$ versus $E_{\mathrm{C}-\mathrm{S}-\mathrm{H}}=47 \mathrm{GPa}$ ); they are stopped by the quartz sand grains $\left(E_{\mathrm{SiO} 2}=70 \mathrm{GPa}>E_{\mathrm{C}-\mathrm{S}-\mathrm{H}}=47 \mathrm{GPa}\right)$. The Young's modulus values given here (Fig. 7) were measured by Velez et al. [32] and Sorelli et al. [25] for the anhydrous compounds and by Vandamme et al. [33] for the hydrates. The path of the cracks can differ from one SEM study to another. It depends on the sample preparation of the fractures for SEM observations. If the applied strain is very high (the case of Moser et al. [24]), the crack pass through both the hydrates ( $E=47 \mathrm{GPa}$ ) and the sand grains ( $E=70 \mathrm{GPa})$. If the strain is lower (our case), the cracks pass only trough the paste, running through the $\mathrm{C}-\mathrm{S}-\mathrm{H}$ and bypassing the anhydrous grains which have the highest Young's modulus ( $E=125-145 \mathrm{GPa})$. We found [11] that the Young's modulus is higher with crushed quartz for UHPC(4-5) than without crushed quartz for UHPC(1-3). Concerning the higher value for UHPC4, two hypotheses can be proposed: (i) a reinforcement of the Young's modulus of the paste, more efficient when the crushed quartz is homogeneously distributed, (ii) a decreasing of the Young's modulus of the paste (UHPC5), related to the replacement of the high modulus of belite by the lower modulus of $\mathrm{C}-\mathrm{S}-\mathrm{H}$. A lower endogenous shrinkage was measured [11] for the UHPC4 samples. Such a result is consistent with a higher Young's modulus, which opposes the contraction of the pores at an early age, under the tensile forces effect due to the water desaturation of the porous network. 


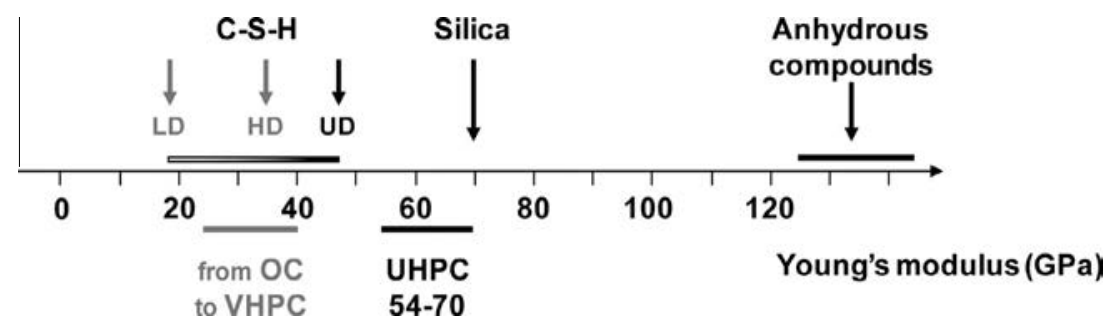

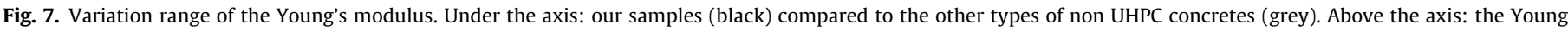
modulus of the various components of a concrete. The values are the values given by Velez et al. [33], Sorelli et al. [25] and Vandamme et al. [34].

\subsection{Effect of polycarboxylate on the hydration of silicates}

The decrease in the belite content observed in the case of $2 \%$ of superplasticizer seems to be only due to an action of polycarboxylate in presence of the cement and silica fume used. Usually, belite hydration starts much later, after a 2 or 3-weeks (dormant period), compared to a few hours for alite. With the low water quantity used here, the hydration reaction of belite should not have occurred. Consequently, the detection of a decrease of the belite content in UHPC $\left(5-3^{\prime}\right)$ can have two possible causes: either the activation of the hydration reaction of belite or an inhibition of the alite dissolution.

A polycarboxylate is made of a main chain of $\mathrm{COO}^{-}$groups - the backbone - with grafted side chains of polyethylene groups. The main chain, negatively charged, allows electrostatic adsorption on positively charged particles, ensuring electrostatic and/or steric repulsion forces between particles. The PCE mainly consumed by the ettringite, resulting from the hydration reaction of $\mathrm{C}_{3} \mathrm{~A}$ and gypsum, has been widely considered in the literature.

But the cement used here, as is usual for UHPC, contains very low $\mathrm{C}_{3} \mathrm{~A}$ percentages (2.7 wt.\% compared to $8-12 \mathrm{wt} . \%$ in usual compositions) and $\mathrm{C}_{4} \mathrm{AF}$ seems to have slightly reacted. The polycarboxylate effect for low $\mathrm{C}_{3} \mathrm{~A}$ content cement on the reactivity of silicates is less understood. Moreover, silica fume is present in our study. Microsilica is known to accelerate the silicate hydration process whereas the polycarboxylate superplasticizer is a strong retardant for silicate hydration. Using model pastes made of $\beta$-belite, colloidal nanosilica and PCE, Björnström and Panas [34] clearly observed an acceleration of the hydration of belite. Using a real UHPC, with standard microsilica, standard cement and PCE, we confirm this result on standard materials.

\section{Conclusion}

This paper compares the microstructure of five UHPC formulations intended for extrudability, in order to highlight the macroscopic properties. The varying parameters were (i) the content in polycarboxylate superplasticizer and (ii) the substitution of silica fume (25\%) by crushed quartz in UHPC with $\mathrm{W} / \mathrm{C}$ of 0.16 . The macroscopic variations in terms of rheology and extrusion, shrinkage, mechanical properties and durability-already published-have been highlighted here at the microscopic scale.

Whereas no visible change on the microstructure is observed without crushed quartz and within the range of compositions in polycarboxylate from $0.5 \%$ to $1.8 \%$, an addition from $1.8 \%$ to $2 \%$ of polycarboxylate causes strong effects on the microstructure in presence of crushed quartz.

The first effect concerns the dispersion of quartz. Quartz is well dispersed in UHPC4 samples (1.8\% PCE) whereas it is only located in the ITZ sand grains in UHPC5 samples (2\% PCE).

The second very interesting effect concerns the reactivity of one of the two major constituents of the cement usually used in UHPC. The belite phase content strongly decreases when the addition of polycarboxylate content is modified from $1.8 \%$ to $2 \%$. This effect is only due to the superplasticizer percentage and not to the crushed quartz. This result appears to be related to the simultaneous presence of several components of UHPC: slightly milled cement with low $\mathrm{C}_{3} \mathrm{~A}$ percentage, silica fume and low $\mathrm{W} / \mathrm{C}$ with PCE.

While solutions to accelerate the reactivity of belitic cements are hot topics today, this study provides an alternative solution to improve the short-term performance of this type of cement. Further investigations are in progress varying the cement and superplasticizer.

\section{Acknowledgements}

The authors would like to thank warmly Prof. Henri Van Damme for fruitful discussions and Dr. Travis Wade for his kind linguistic assistance.

\section{References}

[1] Richard P, Cheyrezy M. Reactive powder concretes with high ductility and 200-800 MPa compressive strength. ACI Special Pub 1994;144(24):507-18.

[2] SETRA. AFGC, Bétons Fibrés à Ultra-Hautes Performances. Recommandations provisoires. Association Francaise de Génie Civil, service d'Études techniques des routes et autoroutes; 2002

[3] Richard P, Cheyrezy M. Composition of reactive powder concretes. Cem Concr Res 1995;25(7):1501-11.

[4] de Larrard F, Sedran T. Optimization of ultra-high-performance concrete by the use of a packing model. Cem Concr Res 1994;24(6):997-1009.

[5] Cheyrezy M. Des matériaux innovants pour des ouvrages économiques. SIA D0160 - Progrès dans la conception des ouvrages en béton. Lausanne, Switzerland; 1999. p. 47-54.

[6] Acker P, Behloul M. Ductal ${ }^{\circledR}$ technology: a large spectrum of properties, a wide range of applications. In: 1st International symposium on ultra-high performance concrete. Germany: Kassel; 2004. p. 11-23.

[7] Vernet CP. Ultra-durable concrete: structure at the micro- and nanoscale. MRS Bull 2004;29(5):324-7.

[8] Morin V, Cohen Tenoudji F, Feylessoufi A, Richard P. Superplasticizer effects on setting and structuration mechanisms of ultrahigh-performance concrete. Cem Concr Res 2001;31(1):63-71.

[9] Feylessoufi A, Tenoudji FC, Morin V, Richard P. Early ages shrinkage mechanisms of ultra-high-performance cement-based materials. Cem $\mathrm{Concr}$ Res 2001;31(11):1573-9.

[10] Cherkaoui K, Courtial M, Dunstetter F, Khelidj A, Mounanga P, de Noirfontaine MN. Early-age volume changes of extrudable reactive powder concrete. In: Brémand $\mathrm{EbF}$, editor. 14th International conference on experimental mechanics - ICEM 14. Poitiers, France: EPJ Web of Conferences; 2010. p. 23005.

[11] Mounanga P, Cherkaoui K, Khelidj A, Courtial M, de Noirfontaine M-N Dunstetter F. Extrudable reactive powder concretes: hydration, shrinkage and transfer properties. Eur J Environ Civil Eng 2012;16(Supplement 1):99-114

[12] Reda MM, Shrive NG, Gillott JE. Microstructural investigation of innovative UHPC. Cem Concr Res 1999;29(3):323-9.

[13] Garas VY, Kurtis KE, Kahn LF. Creep of UHPC in tension and compression: effect of thermal treatment. Cem Concr Compos; 2012.

[14] Orgass M, Klug Y. Fibre reinforced ultra-high strength concretes. In: 1st International symposium on ultra high performance concrete. Kassel, Germany: University of Kassel; 2004. p. 637-48.

[15] Vellmer C, Gehrke M, Middendorf B. Seeing at the nanoscale: hydration of pozzolanic and cementitious materials. In: 1st International symposium on ultra high performance concrete. Germany: Kassel; 2004. p. 575-86.

[16] Nikolić D, Bojović D, Janković K, Lončar L. Mix design and engineering properties of ultra high performance self-compacting concrete. Fib symposium. Prague; 2011. p. 353-6. 
[17] Wang C, Yang C, Liu F, Wan C, Pu X. Preparation of Ultra-High Performance Concrete with common technology and materials. Cem Concr Compos; 2011.

[18] Klobes P, Rübner K, Hempel S, Prinz C. Investigation on the microstructure of ultra high performance concrete. In: 8th International symposium on the characterisation of porous solids, COPS-VIII. Edinburgh, UK; 2008.

[19] Korpa A, Kowald T, Trettin R. Phase development in normal and ultra high performance cementitious systems by quantitative X-ray analysis and thermoanalytical methods. Cem Concr Res 2009;39(2):69-76.

[20] Nguyen VT. Rice husk ash as a mineral admixture for ultra high performance concrete [PhD thesis]. Delft, The Netherlands: Technische Universiteit Delft; 2011.

[21] Matte V, Moranville M. Durability of reactive powder composites: influence of silica fume on the leaching properties of very low water/binder pastes. Cem Concr Compos 1999;21(1):1-9.

[22] Matte V, Moranville M, Adenot F, Richet C, Torrenti JM. Simulated microstructure and transport properties of ultra-high performance cementbased materials. Cem Concr Res 2000;30(12):1947-54.

[23] Müller U, Meng B, Kühne HC, Nemececk J, Fontana P. Micro texture and mechanical properties of heat and autoclaved ultra high performance concrete (UHPC). In: Fehling ea, (Eds.). 2nd International symposium on ultra high performance concrete. Germany: Kassel; 2008. p. 213-20.

[24] Möser B, Pfeifer C, Stark J. Durability and microstructural development during hydration in ultra-high performance concrete. Concrete repair, rehabilitation and retrofitting II. London: Taylor \& Francis Group; 2009. p. 87-8.

[25] Sorelli L, Constantinides G, Ulm F-J, Toutlemonde F. The nano-mechanical signature of ultra high performance concrete by statistical nanoindentation techniques. Cem Concr Res 2008;38(12):1447-56.
[26] Jensen OM, Hansen PF. Water-entrained cement-based materials: I. Principles and theoretical background. Cem Concr Res 2001;31(4):647-54.

[27] Resplendino J, Petitjean J. Ultra-high-performance concrete: first recommendations and examples of application. ISHPC. Orlando, USA; 2003.

[28] Scrivener KL, Kirkpatrick RJ. Innovation in use and research on cementitious material. Cem Concr Res 2008;38(2):128-36.

[29] de Noirfontaine M-N, Dunstetter F, Courtial M, Gasecki G, Signes-Frehel M. Polymorphism of tricalcium silicate, the major compound of Portland cement clinker: 2. Modelling alite for Rietveld analysis, an industrial challenge. Cem Concr Res 2006;36(1):54-64.

[30] Courtial M, de Noirfontaine M-N, Dunstetter F, Gasecki G, Signes-Frehel M. Polymorphism of tricalcium silicate in Portland cement: a fast visual identification of structure and superstructure. Powder Diffr 2003;18(1): $7-16$.

[31] Maki I, Goto K. Factors influencing the phase constitution of alite in Portland cement clinker. Cem Concr Res 1982;12(1):301-8.

[32] Velez K, Maximilien S, Damidot D, Fantozzi G, Sorrentino F. Determination by nanoindentation of elastic modulus and hardness of pure constituents of Portland cement clinker. Cem Concr Res 2001;31(4):555-61.

[33] Vandamme M, Ulm F-J, Fonollosa P. Nanogranular packing of $\mathrm{C}-\mathrm{S}-\mathrm{H}$ at substochiometric conditions. Cem Concr Res 2010;40(1):14-26.

[34] Björnström J, Panas I. Antagonistic effect of superplasticizer and colloidal nano-silica in the hydration of Alite and Belite pastes. J Mater Sci 2007;42(11):3901-7. 